\title{
CONSIDERAÇÕES SOBRE O TEÍSMO CÉTICO
}

\author{
Sérgio R. N. Miranda \\ Universidade Federal de Ouro Preto
}

Resumo: 0 meu objetivo neste artigo é mostrar que o teísmo cético, particularmente a versão proposta por Wykstra em "O obstáculo humiano aos argumentos indiciários do mal: evitar os males da 'aparência"', não é uma resposta satisfatória para o problema do mal. Para tanto, desenvolvo duas linhas de raciocínio. Em primeiro lugar, argumento que um princípio central na resposta de Wykstra, a condição de acesso epistêmico razoável, não é condição necessária para a evidência; em seguida, mostro que o argumento por analogia proposto por ele falha ou conduz a uma versão social do problema do mal.

Palavras-chave: Teísmo; teísmo cético; problema do mal; evidência.

\begin{abstract}
I argue in this paper that the so-called "skeptical theism" is not an adequate solution to the problem of evil. I start by showing that the two main steps of the argument for the skeptical theism are 1) the understanding of the Condition of Reasonable Epistemic Access (CORNEA) as a necessary condition for evidence and 2) the analogy between the relations God/Human Beings and Parents/Child. Then I argue that CORNEA is not a necessary condition for evidence and that the analogy stated fails or leads to a social version of the problem of evil.
\end{abstract}

Keywords: Theism; skeptical theism; problem of evil; evidence.

\section{Introdução}

Discuto neste artigo uma versão da resposta ao problema do mal denominada "teísmo cético". O problema do mal é basicamente a dificuldade de conciliar a existência de Deus, caracterizado como o Criador soberano, onipotente, onisciente, benevolente, justo e amoroso, com a realidade do mal. O cético teísta responde a esse problema afirmando que a distância epistêmica que separa os seres humanos de Deus é tão grande que nos impede de tomar a realidade do mal como evidência contra a existência de Deus. A minha intenção é mostrar que essa resposta cética, pelo menos tal como ela é formulada por Wykstra em "O obstáculo humiano aos argumentos indiciários do sofrimento: evitar os males da 'aparência", não é satisfatória.

Começo com a exposição do problema do mal e a apresentação da versão do teísmo cético proposta por Wykstra. Na sequência, desenvolvo duas linhas de raciocínio contra essa versão. Em primeiro lugar, mostro que Wykstra propõe uma condição excessivamente forte para a evidência, excluindo casos em que podemos legitimamente reivindicar ter evidência para 
as nossas crenças e afirmações. Em seguida, critico um argumento cético baseado na analogia entre a nossa relação com Deus, por um lado, e a relação de um bebê com os seus pais humanos, por outro. Apresento então uma saída para essa crítica, mostrando que, se ela for admitida, podemos salvar uma parte fundamental da resposta cética ao problema do mal, porém ao custo de gerar uma versão social do argumento antiteísta. Esboço o argumento na conclusão do artigo, propondo que a resposta cética de Wykstra dê lugar a uma investigação das razões positivas que justificam Deus permitir o mal.

\section{O problema indiciário do mal}

A existência do mal é vista como um dos grandes obstáculos à crença teísta, uma vez que a presença indecente e a marca indelével do mal no mundo seriam incompatíveis com a soberania, a grandeza e a bondade de Deus. Embora esse problema tenha sido enfrentado por vários filósofos ilustres do passado, entre os quais Agostinho e Leibniz, que realizaram duas das mais notáveis tentativas de justificar Deus, o problema do mal é ainda uma questão em aberto.

No entanto, reconhecer que o problema do mal é uma questão em aberto não significa dizer que não tenha havido progresso nas discussões filosóficas sobre o assunto e nem que ele não tenha solução. No consenso quase unânime dos filósofos da religião contemporâneos, há duas versões distintas do problema, e uma delas está superada.

A primeira delas é o problema lógico do mal. Trata-se da acusação de que o teísmo é uma doutrina inconsistente, porque, por um lado, afirma a existência de Deus, o soberano todo-poderoso, onisciente, perfeitamente bom, justo e amoroso, mas, por outro, afirma a realidade do mal, particularmente na forma do pecado, e, aparentemente, essas afirmações não podem ser verdadeiras ao mesmo tempo. Em sua Defesa do Livre-arbítrio, Plantinga, lançando mão de um poderoso aparato lógico metafísico propiciado pelos desenvolvimentos da filosofia na segunda metade do século XX, tentou provar que o teísmo é consistente. Essa tentativa, mesmo que não tenha tido pleno êxito, estabeleceu um diagnóstico do problema lógico do mal sobre o qual há consenso quase generalizado: dificilmente pode-se manter um argumento com uma conclusão tão forte quanto a afirmação de que o teísmo é inconsistente e envolve contradição ${ }^{1}$.

A Defesa do Livre-arbítrio é plenamente desenvolvida por Plantinga em: "God, Evil and the Metaphysics of Freedom". In: The Nature of Necessity (New York: Oxford UP, 1974), p.164-193; Uma versão mais simples aparece em "The Problem of Evil". In: God, Freedom and Evil (Grand Rapids, MI: Eerdmans, 1977) p.7-64. Ao longo do tempo, a Defesa do Livre-Arbítrio foi alvo de inúmeras críticas, e entre as mais graves estão as críticas de Howard-Snyder e O'Leary-Howthorne em "Transworld Sanctity and 
Alguns autores concordam com os argumentos de Plantinga na Defesa do Livre-arbítrio, mas alegam que o teísta tem de enfrentar um problema mais difícil, denominado problema indiciário do mal. Trata-se da acusação de que o teísmo, apesar de ser uma doutrina coerente, é implausível, dada a enorme quantidade, diversidade e intensidade dos males que existem no mundo. Essa segunda versão do problema do mal suscitou muitas respostas vigorosas, porém ela é ainda vista como uma questão em aberto.

Uma das formulações mais conhecidas da versão indiciária do problema do mal está no artigo de Rowe "O problema do mal e algumas variedades de ateísmo", publicado originalmente em 1979, e desde então reproduzido em diversas antologias de filosofia da religião. O ponto de partida da sua reflexão é um argumento como o seguinte:

1) Há o mal gratuito;

2) Se Deus existe, não há o mal gratuito;

3) Portanto, Deus não existe.

O mal gratuito é o mal incompreensível, que ocorre sem motivo ou razão, que não traz consigo a ocorrência de nenhum bem ou o impedimento de um mal maior. Assim, a premissa 2) afirma que a existência do Deus teísta não é compatível com a ocorrência do mal que não leva a nenhum bem ou impede um mal maior. E ela parece óbvia dadas as características do Deus teísta: suponha que Deus existe; Deus então cria e rege um mundo no qual os seus propósitos sábios, bons, justos e amorosos serão plenamente realizados; nesse mundo, o mal não ocorre ao acaso, o que seria contrário à soberania divina; Deus permite o mal visando realizar algum dos seus propósitos; portanto, não haveria lugar nesse mundo de Deus para o mal gratuito; portanto, se Deus existe, não há o mal gratuito.

A premissa 1) é mais contenciosa, mas Rowe mantém que há evidência a seu favor, mesmo que essa evidência não seja conclusiva, i.e., mesmo que ela não conduza à certeza de 1). Com efeito, visando apoiar a primeira premissa do argumento ateísta, ele introduz o seguinte cenário: ocorre um incêndio florestal causado por um raio que atingiu uma árvore seca; um cervo é apanhado no incêndio, sofre queimaduras graves e agoniza durante alguns dias até que a morte alivie a sua dor. Acerca desse cenário, Rowe afirma que parece não haver um bem ou um mal maior conectado que justificaria Deus permitir o sofrimento do cervo. Ora, se assumimos que casos análogos acontecem neste mundo, quer dizer, que realmente há casos em relação aos quais parece não haver

Plantinga's Free Will Defense". In: International Journal of Philosophy of Religion, 44, n.1, p.1-21, 1998; e OTTE, R. em "Transworld Depravity and Unobtainable Worlds", Philosophy and Phenomenological Research, 78, n.1, p.165-177, 2009. 
um bem ou um mal maior conectado que justificaria Deus, podemos inferir, com base nessa evidência, que provavelmente há o mal gratuito.

Dado que 2) é verdadeira e 1) é provável, segue-se que é provável que Deus não exista, pelo menos tão provável quanto 1), e que o teísmo é implausível. Certamente, o argumento chega a uma conclusão mais fraca do que a afirmação de que Deus não pode existir, dada a realidade do mal, e que o teísmo é inconsistente, porém não é menos perturbador para o crente ter de admitir essa conclusão.

\section{O Teísmo Cético de Wykstra}

A intuição de que as limitações cognitivas dos seres humanos servem de base para uma resposta ao problema do mal é compartilhada por muitas pessoas, em diferentes épocas e lugares, sendo sugerida na própria Bíblia Sagrada, especialmente quando Jó se dirige ao Senhor dizendo: Sei que podes fazer todas as coisas; nenbum dos teus planos pode ser frustrado. Tu perguntaste: "Quem é esse que obscurece o meu conselho sem conbecimento?". Certo é que falei de coisas que eu não entendia, coisas tão maravilhosas que eu não poderia saber. (Jó 42:1-3)

No entanto, oferecer uma resposta filosófica cética ao problema do mal não é uma tarefa simples, visto que nesse caso a intuição tem de ser levada adiante com argumentos. Pede-se ao filósofo mais do que simplesmente afirmar a disparidade cognitiva entre o ser humano e Deus; ele tem de especificar como e por que razão um argumento ateísta como o de Rowe falha quando afirma ter evidência a favor da afirmação de que efetivamente há o mal gratuito e contra a realidade divina.

Essa é principal a intenção de Wykstra ao propor um argumento centrado na Condição de Acesso Epistêmico Raz̧oável, que, de agora em diante, chamo de CAER. Basicamente, a sua resposta cética consiste na apresentação de CAER como uma condição necessária para que alguém possa reivindicar ter evidência para uma proposição, à qual se segue um argumento para estabelecer que CAER não é cumprida quando Rowe reivindica ter evidência para a premissa 1). Portanto, visto que CAER não é satisfeita, Rowe não estaria autorizado a reivindicar ter evidência para a afirmação de que há o mal gratuito e contra o teísmo, e o seu argumento evidencial falharia no ponto de partida.

CAER é apresentada nos seguintes termos:

Com base na situação cognitiva $s$, um ser humano H está autorizado a afirmar "Parece que $p$ " somente se for razoável para $\mathrm{H}$ acreditar que, dadas as 
suas faculdades cognitivas e o uso que faz delas, se $p$ não fosse o caso, $s$ seria provavelmente diferente do que é em alguma medida discernível para $\mathrm{H}^{2}$.

O seu cerne é a condicional "Se p não fosse o caso, s seria provavelmente diferente do que é em alguma medida discernivel para H". Dela falaremos bastante nesta exposição do argumento cético. No momento quero acentuar o seguinte.

Entendo que a situação cognitiva $s$ é o conjunto formado pelo conhecimento, crenças firmes, memórias, percepções e intuições de um ser humano $\mathrm{H}$ em um determinado momento $t$. Assim, de acordo com Wykstra, esse conjunto pode ser encarado como evidência a favor de uma proposição $p$ somente se for provável haver nele uma diferença nas circunstâncias em que $p$ fosse falsa e essa diferença pudesse ser notada por $\mathrm{H}$.

Podemos agora aplicar CAER para ver se qualquer reivindicação de evidência a favor de uma proposição $p$ é ou não legítima seguindo a seguinte receita: primeiramente, construímos mentalmente um cenário no qual $p$ seria falsa; em seguida, perguntamos se $\mathrm{H}$, encontrando-se nesse cenário, poderia notar alguma diferença na sua situação cognitiva, i.e., se ele notaria alguma diferença no seu conjunto de conhecimentos, crenças fortes, percepções, etc. Caso possa encontrar essa diferença, a reivindicação de evidência para $p$ feita por $\mathrm{H}$ seria legítima; caso contrário, $\mathrm{H}$ não estaria autorizado a fazer essa reivindicação.

A título de ilustração, considere dois exemplos:

1) Suponha que a situação cognitiva envolva partes relevantes do nosso conhecimento comum sobre objetos físicos, como árvores, cadeiras, mesas e casas, e a percepção de uma quaresma a 30m de distância; nessa situação, $\mathrm{H}$ reivindica ter evidência para a afirmação de que há uma quaresma adiante.

2) Suponha agora que a situação cognitiva envolva partes relevantes do nosso conhecimento comum sobre microrganismos e o exame a olho nu da ponta de uma agulha; nessa situação, $H$ reivindica ter evidência para a afirmação de que a ponta da agulha não está contaminada.

No segundo caso, a reivindicação é infeliz, mesmo que a agulha não esteja contaminada. Decerto, supondo que a afirmação sobre a agulha não estar contaminada fosse falsa, ou seja, considerando um cenário em que a agulha estivesse contaminada, nenhum ser humano notaria qualquer diferença entre $s$ relativo a esse cenário e relativo àquela circunstância na qual a agulha não está contaminada; portanto, de acordo com CAER, nenhum ser humano, incluindo $\mathrm{H}$, tem o direito de reivindicar ter evidência para essa afirmação. No

2 WYKSTRA, S. "The Humean obstacle to Evidential Arguments from Suffering: on Avoiding the Evil of Appearances". In: International Journal of Philosophy of Religion, 16, p.85, 1984. 
primeiro caso, contudo, CAER é satisfeita, pois, supondo não haver uma quaresma adiante, um ser humano, incluindo $\mathrm{H}$, notaria uma diferença entre $s$ relativo a esse cenário e relativo à circunstância em que há uma quaresma bem à sua frente: em um caso, $\mathrm{H}$ veria a árvore, no outro, não; em um caso, $\mathrm{H}$ formaria a crença de que há uma quaresma adiante, no outro, não; etc. Portanto, no primeiro caso $\mathrm{H}$ está em posição de reivindicar ter evidência para a sua afirmação de que há uma quaresma adiante.

No segundo caso, $\mathrm{H}$ se veria em uma situação análoga àquela em que alguém quer doar algo que não lhe pertence. Por mais que uma pessoa com a intenção de fazer uma doação aponte para uma casa nas proximidades e, confiantemente, diga para outra "Esta casa agora é sua", se a casa não for propriedade da primeira, a segunda não será a nova proprietária da casa; igualmente, por mais que $\mathrm{H}$ diga "Parece que $p$ " com a intenção de reivindicar a posse de evidência para $p$, se CAER não é satisfeita, $\mathrm{H}$ não tem evidência para $p$.

Wykstra sustenta que ninguém está em uma posição epistêmica favorável quando reivindica ter evidência para a afirmação de que há males gratuitos. Em sua opinião, CAER não é satisfeita no caso apresentado por Rowe em seu artigo e em qualquer outro caso análogo; logo, Rowe, assim como qualquer outro indivíduo humano, não tem evidência para a afirmação de que há o mal gratuito e erra quando reivindica ter evidência.

Para tornar plausível essa opinião, Wykstra tem de responder duas questões. A primeira delas é explicar por que CAER deve ser vista como uma condição necessária para a evidência. A resposta do próprio Wykstra é que a introdução de CAER é motivada por uma condição anterior, chamada de cláusula de aceitação, segundo a qual s é evidência somente se o agente cognitivo aceitar que há uma conexão evidencial entre $s$ e aquilo que acredita, quer dizer, somente se aceitar que $s$ é o que o leva a acreditar que $p$.

O argumento é então o seguinte: se CAER não é satisfeita, o agente cognitivo não diferencia $s$ na circunstância em que $p$ é o caso de $s$ na circunstância em que não $p$ é o caso; se não vê essa diferença, não é razoável para ele aceitar a conexão evidencial entre $s$ e aquilo que acredita, i.e., que $s$ seja o que o leva a acreditar que $p$; nesse caso, pois, a cláusula de aceitação não é cumprida; e se a cláusula de aceitação não é cumprida, $s$ não é evidência para $p$; portanto, se CAER não é satisfeita, $s$ não é evidência para $p$, o que é equivalente a dizer que CAER é condição necessária para a evidência.

A segunda questão é a seguinte: por que temos de admitir que Rowe não é bem-sucedido quando reivindica ter evidência para a afirmação de que há o mal gratuito? Visto que é a aplicação de CAER que nos leva a diagnosticar que Rowe é infeliz na sua reivindicação, a pergunta vem a ser por 
que admitir que não notaríamos qualquer diferença na nossa situação cognitiva $s$ quando a circunstância em que não há um bem justificador de Deus é comparada com um cenário em que há um bem justificador.

Para responder a essa questão, Wykstra oferece um argumento por analogia. Em sua opinião, a distância epistêmica que separa os seres humanos de Deus é análoga à distância epistêmica entre um bebê e os seus pais humanos; ora, um bebê pode discernir alguns dos bens que seus pais the proporcionam, porém dificilmente está em posição de discernir a maior parte dos propósitos bons que existem em conexão com os males que os pais permitem que ele sofra (pense aqui nas temíveis injeções da infância); da mesma forma, embora possamos discernir alguns dos bens divinos, não estamos em posição de discernir a maior parte dos propósitos bons que existem em conexão com os males que Deus permite que soframos; portanto, em cada caso particular de mal, é provável que não possamos discernir o bem visado por Deus que estaria conectado a esse mal.

Esse argumento por analogia encerra a resposta de Wykstra ao argumento ateísta de Rowe. Na próxima seção, considerarei criticamente essa resposta, concentrando a minha atenção na afirmação de que CAER é uma condição necessária para a evidência e na analogia introduzida para justificar por que não podemos legitimamente reivindicar ter evidência a favor da afirmação sobre os males gratuitos.

\section{Considerações sobre o teísmo cético}

Apresento nesta seção duas críticas à versão de Wykstra do teísmo cético que são fortes o bastante para forçar uma revisão do teísmo cético ou a adoção de uma estratégia diferente para responder ao problema do mal. Primeiramente, busco mostrar que CAER não é uma condição necessária para a evidência apresentando casos em que uma pessoa teria evidência para suas crenças e CAER não seria satisfeita. Na sequência, critico o argumento por analogia; busco mostrar que a analogia seres humanos/Deus e bebês/pais humanos, levada um pouco adiante do ponto em que foi deixada, tem um resultado contrário àquele esperado por Wykstra.

\section{a. Consideração sobre o caráter de CAER}

CAER é uma condição necessária da evidência? A resposta a essa pergunta exige primeiramente esclarecer as noções de condição necessária e de evidência. A noção de condição necessária pode ser entendida em termos condicionais: A é uma condição necessária de B se, e só se, B implica A (simbolicamente: $\mathrm{B} \rightarrow \mathrm{A}$ ). Note ainda que a negação de uma condicional é aquilo que ela exclui, ou seja, a conjunção da afirmação da antecedente com a 
negação da consequente; assim, nega-se que A seja uma condição necessária de $\mathrm{B}$ negando-se a condicional $\mathrm{B} \rightarrow \mathrm{A}$, o que fazemos mostrando que a conjunção B \& $\neg$ A é verdadeira. Em relação à noção de evidência, estipulamos que se trata de um conjunto de proposições que são admitidas pelo agente cognitivo como razão para a sua crença em uma outra proposição.

Portanto, se queremos questionar que CAER seja uma condição necessária para a evidência, devemos negar a condicional "há evidência $\rightarrow$ CAER" que afirma só haver evidência se CAER for satisfeita. Negamos essa condicional ao mostrar casos em que há evidência e CAER não é satisfeita. Haveria casos assim? A meu ver, inferências indutivas e abdutivas formam uma classe de casos em que admitimos que uma pessoa baseia as suas crenças em evidência e CAER não é satisfeita. Consideremos primeiro a inferência indutiva.

Suponha que Moe discuta com Larry sobre a forma do bico de uma espécie A de ave brasileira; Moe observa no Rio de Janeiro vários indivíduos da espécie A e constata que todos têm um bico de serra; ele relata as suas observações a Larry, que, apesar disso, fica inseguro quanto à forma do bico, pois, segundo ele, poderia haver formas diferentes em outros locais; Moe amplia a sua investigação, constata que em outros estados brasileiros as aves da espécie A têm um bico de serra e conclui que todas as aves do tipo A têm o bico de serra. O procedimento adotado parece correto; Larry está satisfeito com a pesquisa; mas Moe está realmente em posição de reivindicar ter evidência para a afirmação de que todas as aves da espécie A têm o bico de serra?

Sobre um exemplo análogo de generalização indutiva, McBrayer, discutindo a plausibilidade de CAER, afirma o seguinte:

Acredito que todos os corvos são negros. Tenho evidência indutiva para essa afirmação. Todos os corvos que vi (e vi muitos deles!) eram negros. A minha evidência é sensível ao fato de que todos os corvos são negros? Não. Vá ao mundo mais próximo em que é falso que todos os corvos são negros. Talvez um corvo tenha sofrido uma mutação genética que o tornou albino. É razoável acreditar que a minha situação cognitiva no mundo atual seria de modo discernível diferente da minha situação cognitiva no mundo possível em que nem todos os corvos são negros? Não - as coisas pareceriam do mesmo jeito para mim. Logo, conforme CAER, não tenho evidência para a afirmação de que todos os corvos são negros ${ }^{3}$.

Sem dúvida, a condicional se p não fosse o caso, s seria de alguma maneira diferente do que é em alguma medida discernivel para $H$ é central na formulação de

${ }^{3}$ MCBRAYER, J. "Cornea and Inductive Evidence". In: Faith and Philosophy, 26, n.1, p.84, 2009. 
Wykstra de CAER. Vamos escrevê-la assim: $\neg p \square \rightarrow \neg \mathrm{B}_{\mathrm{H}}(s)$, querendo dizer então que se não $p$ fosse o caso, $H$ não acreditaria encontrar-se em $s$. $\mathrm{Na}$ crítica de McBrayer, assim como em outras objeções ao teísmo cético, ela também tem um peso importante. O ponto de partida dessa crítica é a valoração da condicional em termos de mundos possíveis.

Quando valoramos proposições, atribuímos a elas os valores de verdade $\mathrm{V}$ (verdadeiro) e $\mathrm{F}$ (falso), a partir dos quais podemos calcular o valor de verdade de proposições complexas. Por exemplo, podemos atribuir a $p$ o valor $\mathrm{V}$ e a $q$ o valor $\mathrm{F}$, obtendo então o valor $\mathrm{V}$ para a disjunção $p \mathrm{~V} q$ e $\mathrm{F}$ para a conjunção $p \& q$. Podemos também dizer que uma proposição é verdadeira em algumas circunstâncias e falsa em outras; por exemplo, Brasília é a capital do Brasil é verdadeira nas circunstâncias atuais, mas seria falsa em um cenário alternativo no qual o Rio de Janeiro ainda fosse a capital do país. Vamos chamar as circunstâncias atuais e cenários alternativos de mundos possíveis. A ideia é então que as proposições constituintes da condicional $\neg p$ $\square \rightarrow \neg \mathrm{B}_{\mathrm{H}}(s)$, i.e., $\neg p \mathrm{e} \neg \mathrm{B}_{\mathrm{H}}(s)$, são verdadeiras em alguns desses mundos possíveis e falsas em outros. No entanto, como devemos avaliar a condicional como um todo? Distribuídos os valores de verdade de $\neg p$ e $\neg \mathrm{B}_{\mathrm{H}}(s)$ nos diferentes mundos possíveis, o modo usual de chegar ao valor de verdade da condicional é considerar se nas circunstâncias e cenários alternativos mais parecidos com o mundo atual (ou seja, nos mundos possíveis mais próximos) em que $\neg p$ é verdadeira, $\neg \mathrm{B}_{\mathrm{H}}(s)$ é igualmente verdadeira. Se for esse o caso, a condicional é verdadeira; do contrário, ela é falsa.

Voltando ao nosso exemplo, parece claro que Moe acumulou evidência em número e grau suficiente para inferir que todas as aves da espécie A têm o bico de serra. Contudo, aplicando CAER, deveríamos negar que Moe esteja em posição de reivindicar ter evidência para a sua afirmação, uma vez que, em um cenário no qual fosse falsa a afirmação sobre as formas dos bicos da espécie A, i.e., em um cenário no qual um indivíduo ou mesmo um pequeno bando isolado dessa espécie tenha nascido com uma mutação genética e uma forma diferente de bico, Moe dificilmente notaria uma mudança na sua situação cognitiva. Ele ainda acreditaria, baseado na sua situação cognitiva, que todas as aves A têm o bico de serra.

A crítica de McBrayer é a seguinte: a condicional $\neg p \square \rightarrow \neg \mathrm{B}_{\mathrm{H}}(s)$ é interpretada em termos de mundos possíveis; nessa interpretação, ela exclui casos claros em que o agente cognitivo tem evidência para as suas crenças, como é o caso da inferência de Moe sobre os bicos das aves A; portanto, ela não é aceitável; visto que essa condicional é a parte central de CAER, essa condição também deve ser recusada. 
McBrayer não segue adiante, mas é claro que esse resultado negativo pode ser levado adiante com a consideração de outros tipos de raciocínio em que a evidência apresentada a favor de uma hipótese é menos do que conclusiva, ou seja, quando, a despeito da evidência, há ainda uma margem de erro.

Considere o exemplo de um tipo de inferência não conclusiva chamada de "abdução" ou "inferência para a melhor explicação". À noite, Larry come os últimos cookies do pote, sabe que isso deixará Moe muito irritado, levando-o a praguejar. Quando acorda de manhã, Larry ouve Moe praguejando, pensa que ele está irritado porque descobriu que os últimos cookies do pote foram devorados à noite. Essa é uma sequência de inferências para a melhor explicação bastante razoável: do fato de Moe praguejar para a conclusão que melhor explica o seu comportamento, i.e., a de que ele está irritado, e daí para a conclusão que melhor explica a sua irritação, i.e., a de que ele descobriu que não tem mais cookies no pote.

Há vários elementos nessa história que caracterizam a evidência de Larry para acreditar que Moe descobriu que não há cookies no pote: o comportamento verbal de Moe, o fato de Moe começar a praguejar logo de manhã, as crenças de Larry acerca da psicologia de Moe, o conhecimento comum sobre o comportamento de objetos físicos, o fato da hipótese de Larry ser bem simples e óbvia etc. Nada disso precisa mudar em uma circunstância em que, embora tenha notado que os cookies se foram, Moe não esteja realmente irritado por causa deles; na verdade, ele dormiu mal à noite por causa de um pesadelo, do qual não se lembra, e pode até mesmo aceitar a explicação de Larry para a sua condição.

O que esse exemplo sugere é que há na proposta de Wykstra a suposição de que qualquer alteração no valor de verdade da conclusão de uma inferência tem de refletir na situação cognitiva do agente. Quando isso não ocorre, como no exemplo anterior, Wykstra só pode salvar a sua posição com a sugestão de que Larry realmente não tem evidência para a sua hipótese de que Moe está irritado por causa dos cookies. Mas a nossa intuição original não se altera: Larry tem evidência para acreditar que o motivo real da irritação de Moe sejam os cookies desaparecidos; ele inferiu corretamente com base em evidência. Nesse caso, portanto, se não houver nenhuma outra motivação para CAER além da alegação de que ele permite uma resposta ao problema do mal, a sugestão de Wykstra deve ser recusada.

O que vimos então é que intuitivamente atribuiremos a Moe no primeiro caso e a Larry no segundo a posse da evidência, a despeito de não haver uma mudança discernível na situação epistêmica do agente em uma circunstância em que a conclusão inferida fosse falsa. Assim, CAER falha em 
propiciar um teste adequado da evidência no caso das induções e inferências para a melhor explicação. Acredito que ele também falha nos demais raciocínios em que a evidência não é conclusiva, como no caso das analogias e inferências causais, devendo, pois, ser recusada como condição necessária da evidência.

\section{b. Consideração sobre a analogia de Wykstra}

Argumentos por analogia são inferências de similaridades relevantes entre indivíduos ou grupos para outras similaridades desses indivíduos ou grupos. Nesses argumentos, pode-se inferir da constatação que os indivíduos do tipo $a$ e $b$ são $\mathrm{F}$ e que os indivíduos do tipo $a$ são $\mathrm{G}$ para a afirmação de aqueles do tipo $b$ são G. Por exemplo, se as características morfológicas dos tipos $a$ e $b$ de aves são similares e as aves do tipo $a$ são carnívoras, pode-se, corretamente, concluir por analogia que as aves do tipo $b$ também são carnívoras.

$\mathrm{Na}$ filosofia, os argumentos por analogia são frequentes, e o mais famoso deles talvez seja o argumento do desígnio. Nesse argumento, da constatação de que há similaridades entre o universo e artefatos humanos como relógios e smartphones, em particular o fato de eles possuírem diversos componentes que funcionam juntos para a realização de um fim, e que estes últimos são fabricados pelo engenho humano, conclui-se que o primeiro seja igualmente a obra de um artífice, só que divino.

Wykstra usa a similaridade que haveria entre as relações de um bebê com os seus pais humanos e os seres humanos com Deus para estabelecer que os seres humanos não estão em posição de conhecer os bens visados por Deus em todos os casos de males. A similaridade constatada é que nos dois casos haveria bondade, generosidade, amor e carinho na relação, mas também uma enorme distância epistêmica separando o bebê e seus pais humanos, por um lado, e Deus e os seres humanos, por outro. Ora, visto que o bebê não está em posição de saber qual é o bem visado pelos pais quando eles permitem o seu sofrimento, quando, por exemplo, permitem que ele seja picado por uma agulha visando imunizá-lo contra doenças, Wykstra conclui, por analogia, que nós (inclusive Rowe) igualmente não estamos em posição de saber qual é o bem visado por Deus em todos os casos de males.

Vamos agora avaliar esse argumento.

Sabemos que argumentos por analogia falham quando as similaridades constatadas não são relevantes para a conclusão. Considere, por exemplo, uma situação em que alguém parte da constatação de que os membros de um grupo A usam óculos e gostam muito de ler Kant, que os membros do grupo B também usam óculos, para inferir que os membros de 
grupo B também gostam muito de ler Kant. A inferência é simplesmente ridícula, pois usar óculos não tem nada a ver (i.e., não é relevante) para a propriedade de gostar de ler Kant.

O argumento de Wykstra não é desse tipo, e, certamente, parece haver relevância nas similaridades constatadas: a distância cognitiva que separa o bebê dos pais e os humanos de Deus é certamente relevante para determinar se os primeiros membros dos dois pares (bebê e seres humanos) têm acesso pleno, ou, pelo menos, significativo, às intenções e propósitos dos segundos (pais humanos e Deus). Portanto, essa não é a melhor via para criticar o argumento por analogia de Wykstra.

Outro modo de questionar se argumentos por analogia são bons é manter que há dissimilaridades relevantes entre os elementos comparados a fim de enfraquecer a inferência das similaridades relevantes constatadas para mais similaridades. Por exemplo, pode-se certamente manter que há similaridades entre os órgãos do corpo humano e as peças de uma máquina; contudo, inferir daí que os órgãos humanos são comercializáveis assim como as peças de uma máquina é inadequado, pois há nesse caso dissimilaridades entre os órgãos humanos e as peças de uma máquina, relacionadas à dignidade humana, que são de extrema relevância para a questão da comercialização de órgãos humanos.

Haveria alguma dissimilaridade relevante entre a relação bebês e pais humanos e a relação dos seres humanos com Deus? Considere as ideias de crescimento pessoal, cognitivo, afetivo e moral, e o desenvolvimento e aprofundamento da relação entre o bebê e os seus pais humanos. Certamente, há espaço na relação entre bebês e pais humanos para o crescimento pessoal, cognitivo, afetivo e moral, bem como para o desenvolvimento e aprofundamento da relação do bebê com seus pais. A consequência disso é o reconhecimento e gratidão por parte do bebê dos bens visados pelos pais quando eles permitiram que ele sofresse. Chamarei essa nova situação de otimização da situação cognitiva, afetiva e moral.

Há espaço para a otimização dos seres humanos em sua relação com Deus? Se não há tal espaço, a analogia proposta por Wykstra falha miseravelmente: a distância epistêmica entre os seres humanos e Deus não pode ser vista como similar àquela entre o bebê e seus pais, visto que aquilo que separa o bebê dos seus pais é uma diferença de grau, enquanto a distância entre os humanos e Deus seria uma distância de tipo, similar, antes, à distância epistêmica que separa os humanos das bactérias. Wykstra poderia então propor uma nova analogia da relação que têm com Deus com a relação entre os seres humanos e as bactérias? Obviamente, essa não é uma boa saída, porque, nesse caso, haveria outras dissimilaridades relevantes e o argumento também 
fracassaria. Além disso, recusar o espaço para a otimização parece contrário às melhores interpretações sobre o que é esperado dos seres humanos na relação com Deus.

Para salvar a analogia de Wykstra, ficamos assim com a segunda alternativa. Mas como elaborar a otimização da relação entre os seres humanos e Deus de tal modo que possamos em algum momento ter clareza sobre uma parcela relevante dos bens visados na criação? Como é possível para um indivíduo finito compreender melhor o campo moral dos bens e dos males envolvidos na criação, mesmo que não seja na sua totalidade?

Uma alternativa seria apelar para o juízo de pessoas extremamente sensíveis com um senso moral aguçadíssimo. Esses experts formariam um padrão que aceitaríamos como guia para a compreensão mais abrangente do campo dos bens e dos males. A favor dessa alternativa pesa o fato de que há realmente pessoas assim na história da humanidade: as diversas reencarnações de Buda, todos os profetas bíblicos, Maomé, os santos e mártires das igrejas católicas romana e ortodoxa, o atual Papa Francisco, e assim por diante.

Contudo, esse apelo não resolve o problema, pois os experts morais podem ter opiniões divergentes, e teríamos de decidir então que opinião deveríamos adotar como guia. Nesse caso, nós mesmos deveríamos ter um conhecimento do campo moral amplo o bastante para distinguir os juízos mais corretos e justos, identificar os experts morais e excluir os que falsamente reivindicam essa competência.

Podemos conceder ao cético que atualmente não temos esse discernimento amplo. A nossa pergunta é então se haveria um modo de incrementar a nossa capacidade de discernir o bem e o mal e ampliar a nossa compreensão do campo moral de tal modo que possamos aproximar ou mesmo ultrapassar o grau de correção dos juízos de um verdadeiro expert.

Para incrementar essa capacidade não é necessário dotar os indivíduos com poderes especiais (pois introduziríamos assim uma dissimilaridade com a relação entre bebês e os pais humanos que seria contrária à analogia de Wykstra); a probabilidade de acerto de um juízo aumenta quando ele é o juízo de um grupo de pessoas ou instituição humana, ou seja, essa probabilidade aumenta na proporção em que os juízos individuais são agregados, aproximando-se, no limite, da probabilidade máxima de acerto. É exatamente a superioridade de juízos agregados sobre juízos individuais que justifica a decisão sobre crimes ser preferencialmente realizada por um júri popular e não só por um único expert em questões legais e morais: a probabilidade do júri chegar a uma decisão correta sobre a culpa ou inocência de uma pessoa acusada de crime violento, por exemplo, é maior do que a probabilidade de acerto de um único indivíduo, mesmo do expert. 
Um teorema matemático elegante proposto por Condorcet, conhecido como "teorema do júri", garante esse resultado. Mas note que o resultado é gerado somente se algumas condições são cumpridas, entre as quais quero ressaltar a seguinte: os jurados devem ter alguma competência para julgar, o que quer dizer, em termos probabilísticos, que cada juízo individual tem de ter pelo menos 51 por cento de chance de estar correto. Embora não tenhamos um conhecimento amplo, temos de ter, pelo menos, um conhecimento mínimo do campo moral.

A proposta então é otimizar socialmente e coletivamente a situação cognitiva dos seres humanos. Solidificado ao longo da história humana e perpassando as diferentes gerações e tradições culturais, um juízo de valor, gerado pela agregação de muitos juízos individuais, tem boas chances de ser verdadeiro. Desse modo, teríamos um acesso mais amplo e profundo do campo moral, possibilidade que tornaria a nossa relação com Deus similar àqueles dos seres humanos entre si, particularmente dos pais com os filhos, e diferenciaria essa relação daquela que existe entre os outros animais, mesmos daqueles que também vivem em grupos.

Dada essa saída, a analogia de Wykstra poderia ser salva e a resposta ao argumento de Rowe ser mantida, não fosse o seguinte: ao permitir o crescimento, desenvolvimento e aprofundamento da nossa relação com Deus, ao salvar a analogia de Wykstra apelando para a competência mínima dos seres humanos em relação ao campo moral e para a agregação de juízos, teríamos de conceder que é possível em algum momento chegarmos a veredito sobre o mal gratuito e a realidade divina.

Tal resultado seria contrário às intenções de Wykstra, que poderia agora ou manter a sua posição inicial, o que custaria a analogia e uma parte relevante do seu argumento, ou abrir mão dela, salvando a analogia, porém abrindo mão da sua posição inicial e permitindo a construção de uma versão diferente do argumento de Rowe contra o teísmo, uma versão baseada na agregação de juízos. Vejamos na sequência como seria esse argumento.

\section{Conclusão}

Rowe infere a partir do caso do cervo e outros casos análogos que há o mal gratuito. O cético teísta afirma que ele não está em posição de reivindicar ter evidência para essa afirmação sobre o mal gratuito. Central no argumento do cético é a ideia de que a distância epistêmica entre os seres humanos e o Criador impede a inferência de Rowe, uma vez que a base para realizar essa inferência ficaria muito restrita.

Contudo, argumentei que essa distância pode ser diminuída, embora não seja anulável. Com efeito, podemos desenvolver estratégias que 
proporcionem um acesso mais amplo e profundo do campo dos bens e males e probabilidades maiores de acerto. Agregando juízos de pessoas minimamente competentes, chegamos a juízos comuns com forte chance de serem verdadeiros.

Suponha agora que seja instituída uma sociedade de pesquisa sobre os bens e males constituída de pessoas agnósticas. Vamos chamá-la então de Sociedade Agnóstica ou SA. Os membros de SA não seriam experts do campo moral, porém podemos conceder que eles têm alguma competência para julgar o bem e o mal, ou seja, o juízo deles pode tem grau mínimo de probabilidade de ser verdadeiro, digamos, 0.51 . Podemos agregar o juízo dos membros de SA ao longo de eras visando um juízo final da própria instituição.

Imaginemos que SA investigue o campo dos bens e males durante eras, chegando ao final a um percentual elevado de membros que julgaram certos males no mundo como injustificáveis. Dado que a probabilidade de acerto aumenta com a agregação de juízos no tempo, mesmo que a probabilidade de acerto de cada membro seja muitíssimo modesta, pouco superior ao limiar da competência, o juízo final de SA seria uma razão conclusiva para abrirmos mão da crença teísta. Essa é a meu ver a consequência de aceitar a saída mencionada no fim da seção anterior visando salvar o argumento por analogia de Wykstra.

Evidentemente, não precisamos adiantar o juízo dessa sociedade agnóstica e nem prever que ela se tornará ao final uma sociedade ateísta, mesmo que esse pareça ser um destino inevitável se focamos a atenção exclusivamente no mal e nas suas consequências. $\mathrm{O}$ que argumentei até aqui apenas indica o fracasso de uma versão de teísmo cético. Uma boa defesa do teísmo deveria a meu ver mostrar por que os membros da sociedade agnóstica não chegariam à conclusão de que Deus não existe, ainda que cada um deles julgue haver a probabilidade modesta de 0.51 de que há males sem propósito. Nessa defesa o teísta mostraria que temos boas razões ou que há garantia para a crença teísta, contrabalançando assim a evidência do $\mathrm{mal}^{4}$.

\section{Referências}

ACHINSTEIN, P. “The Concepts of Evidence”. In: Mind, 87, n. 345, p.22-45, 1978.

HOWARD-SNYDER, D. e O'LEARY-HAWTHORNE, J. "Transworld Sanctity and Plantinga's Free Will Defense". In: International Journal Philosophy of Religion, 44, n.1, p.1-21, 1998.

${ }^{4}$ Agradeço a Luiz Helvécio Marques Segundo e Pedro Merlussi pela leitura e os comentários da versão prévia deste artigo. 
MCBRAYER, J. "Cornea and Inductive Evidence". In: Faith and Philosophy, 26, n.1, p.77-86, 2009.

NITZAN, S. "Which rule is better: the expert rule or the simple majority Rule?". In: NITZAN, S. Collective Preference and Choice, Cambridge: Cambridge University Press, p.201-224, 2010.

OTTE, R. "Transworld Depravity and Unobtainable Worlds", Philosophy and Phenomenlogical Research, 78, n.1, p.165-177, 2009.

PLANTINGA, A. The Nature of Necessity. New York: Oxford University Press, 1973.

. God, Freedom and Evil. Grand Rapids, MI: Eerdmans, 1977.

ROWE, W. "The Problem of Evil and Some Varieties of Atheism". In: American Philosophical Quarterly, 16, p.335-341, 1979.

WYKSTRA, S. "The Humean obstacle to Evidential Arguments from Suffering: on Avoiding the Evil of Appearances". In: International Journal of Philosophy of Religion, 16, p.73-93, 1984.

E-mail: sergiornmiranda@me.com

Recebido: 29/09/2016

Aprovado: 24/04/2017 